\title{
True Heterotopic Bone in the Paralyzed Patient
}

\author{
Caroline E. Blane, M.D., C.M., F.R.C.P. (C) ${ }^{1 *}$, and Inder Perkash, M.D. ${ }^{2}$ \\ ${ }^{1}$ Division of Diagnostic Radiology and ${ }^{2}$ Spinal Cord Injury Center, Stanford University School of Medicine, Veterans Administration \\ Hospital, Palo Alto, California, USA
}

\begin{abstract}
In past years the clinical and radiologic presentation of true heterotopic bone in the paralyzed patient has been confused with osteomyelitis, neoplasm, trauma, and thrombophlebitis. We reviewed 376 paralyzed patients' roentgenographic files and found 78 patients with soft tissue ossification unassociated with infection, neoplasm, or underlying fractures, which we called true heterotopic bone. From this population the usual spectrum of radiologic findings is described, so that the radiologist may separate roentgenographically a group of patients from other types of ectopic ossification.
\end{abstract}

Key words: Myositis ossificans - Paraplegia - Quadriplegia

The term heterotopic bone implies ossification in an abnormal location. Ectopic ossification is predominantly associated with neoplasia, infection, and trauma. Reports of heterotopic bone in paraplegic and quadraplegic patients have appeared in the literature, under many titles; neurogenic ossifying fibromyopathy [29], para-osteo-arthropathy [25], and ectopic ossification [23]. Despite the obvious radiologic findings in these cases, the criteria for true heterotopic bone in the paralyzed patient are not well defined.

The clinical presentation of true heterotopic bone formation, a benign condition which requires no specific treatment, is difficult to differentiate from osteomyelitis, neoplasm, and thrombophlebitis [16, 23, 32]. The purpose of this paper is to present the usual spectrum of radiologic findings associated with true

* Present address and address for reprint requests: C.E. Blane, M.D., Division of Pediatric Radiology, C.S. Mott Children's Hospital, University of Michigan Medical Center, Ann Arbor, MI 48109, USA heterotopic bone in paralyzed patients. Familiarity with the usual presentation will help the radiologist to alert the clinician to consider trauma, infection, or neoplasm when an atypical or unusual roentgenographic presentation is encountered.

\begin{abstract}
Methods
The Spinal Cord Injury Center at the Veterans Administration Hospital in Palo Alto had 588 patients listed at the time of this study. Of these, 376 Patients had available roentgenographic files that included views of both hips. These films were felt to be a minimum requirement for inclusion in the study, since the major area of involvement with heterotopic bone is the hip [6]. All roentgenographic files were reviewed. The cases with osseous deposition within the soft tissues were then correlated with the clinical charts. No patient had a bone tumor. Three cases of osteomyelitis associated with new bone formation were excluded. All cases with new bone formation related directly to underlying fractures were excluded. The remaining group of 78 patients had heterotopic bone formation of unknown etiology. This group we called true heterotopic bone.
\end{abstract}

\section{Resuits}

All of the 78 patients were male. Forty-two were paraplegic and 36 were quadraplegic. The level of injury

Table 1. Injury leading to paralysis

\begin{tabular}{lcc}
\hline Type of injury & No. of cases & Percent \\
\hline Diving & 9 & 11.5 \\
Motor vehicle accident & 35 & 44.9 \\
Gun and missile & 15 & 19.3 \\
Fall & 4 & 5.1 \\
Crush & 4 & 5.1 \\
Other & 11 & 14.1 \\
\hline Total & 78 & 100 \\
\hline a Other included two congenital spinal stenosis, four infection, &
\end{tabular}



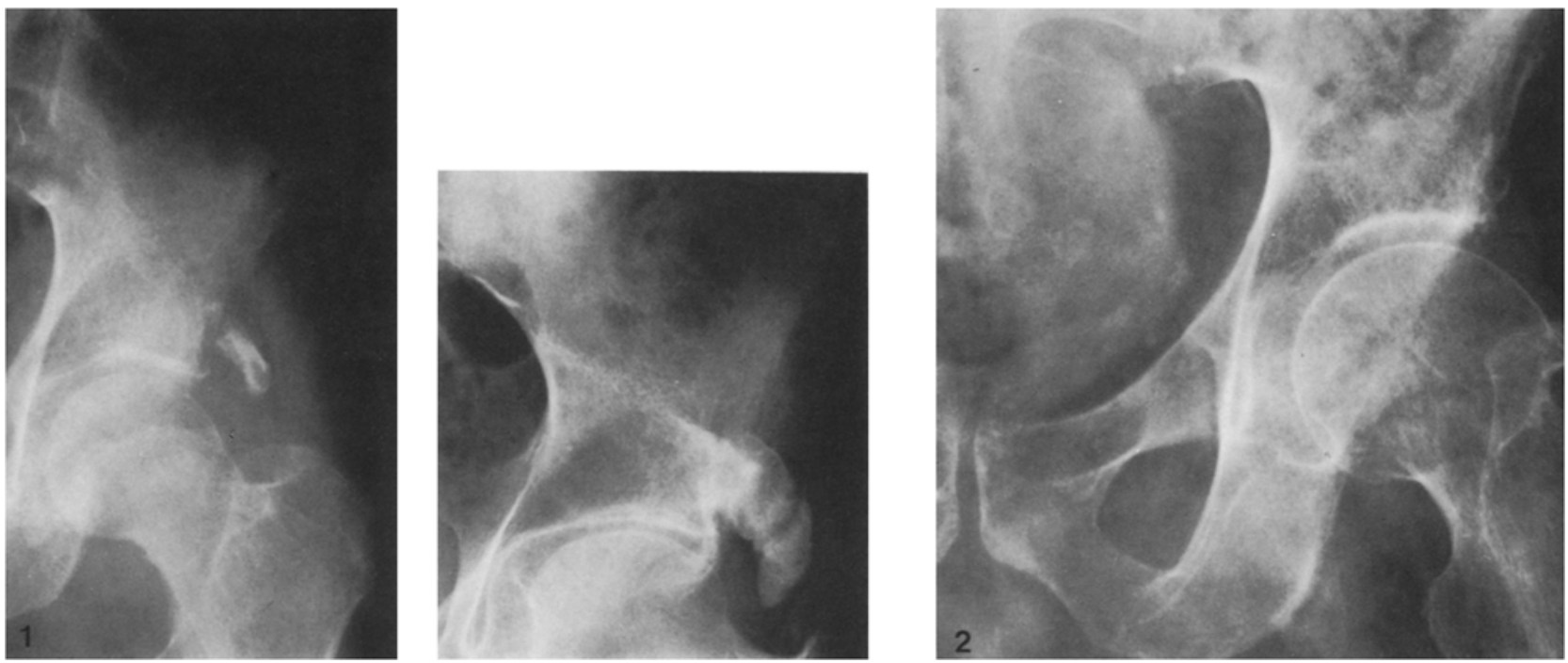

Fig. 1. Heterotopic bone about the anterior inferior iliac spine or rectus femoris in two different paralyzed patients

Fig. 2. Heterotopic bone about the ischium or hamstring or adductor muscles in a paralyzed patient
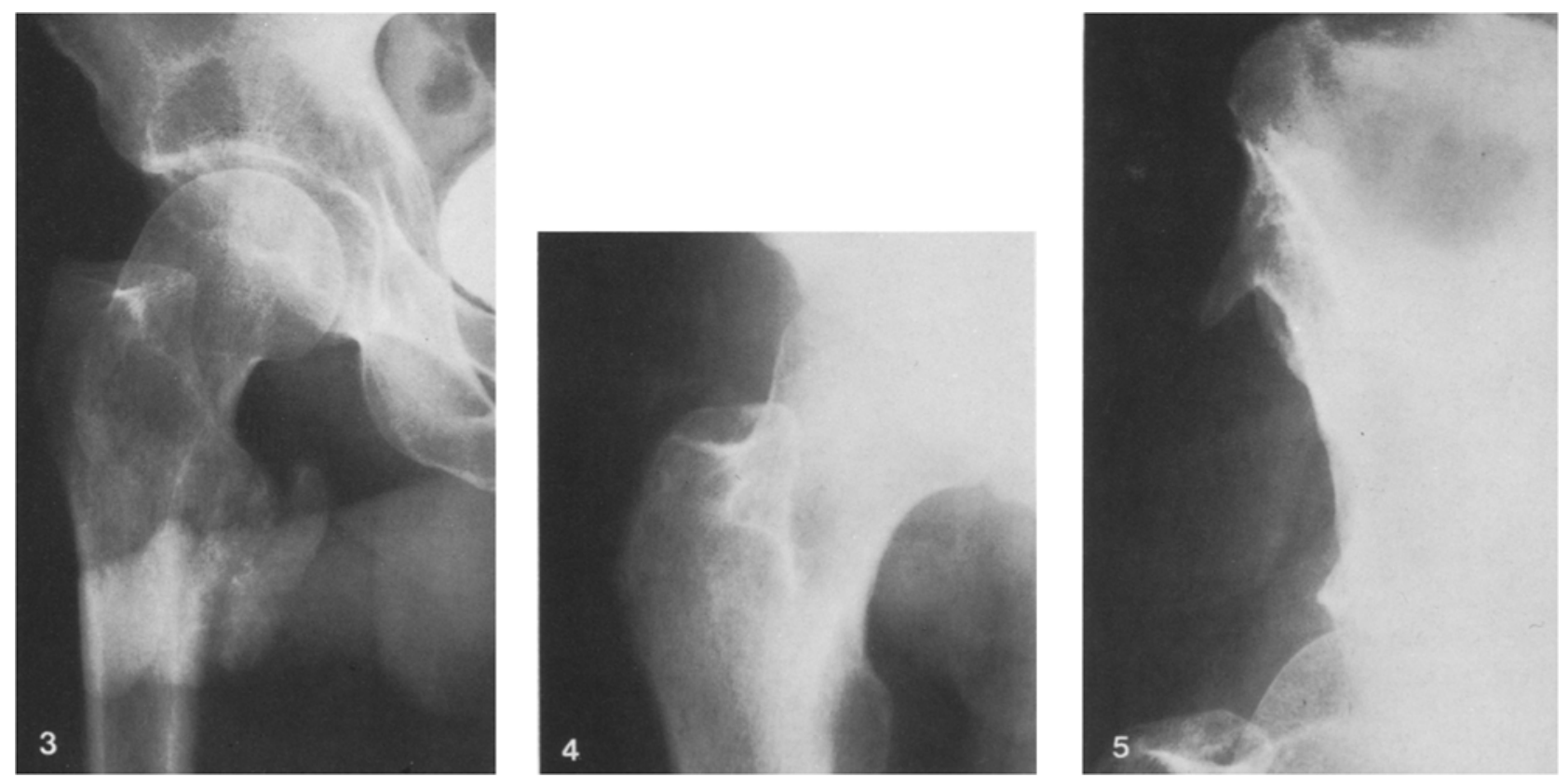

Fig. 3. Heterotopic bone around the lesser trochanter or iliopsoas in a paralyzed patient

Fig. 4. Heterotopic bone around the greater trochanter or gluteus medius in a paralyzed patient

Fig. 5. Heterotopic bone about the anterior superior iliac spine or sartorius in a paralyzed patient

varied from $\mathrm{C} 4$ to $\mathrm{L} 4$. Both spastic and flaccid paralysis were present. The mean age of the patients was 43 years with a range of 24 to 70 years. The duration of the paralysis ranged from six months to 34 years. The types of injury leading to the paralysis are listed in Table 1. The incidence of true heterotopic bone in this study is 78 out of 376 or $20.7 \%$.

The true heterotopic bone formation in the spinal cord injury patient was classified in relation to the ligaments, muscles, or site of bony attachment where 
Table 2. Location of heterotopic bone in 78 paralyzed patients

\begin{tabular}{|c|c|c|c|c|c|c|c|}
\hline \multirow[t]{2}{*}{ Area involved } & \multicolumn{3}{|c|}{28 patients with single focus } & \multicolumn{3}{|c|}{50 patients with multiple foci } & \multirow[t]{2}{*}{ Total } \\
\hline & Right & Left & Right and Left & Right & Left & Right and Left & \\
\hline Rectus femoris & 4 & 5 & 2 & 9 & 6 & 22 & 72 \\
\hline Hamstring & 2 & 1 & 3 & 9 & 5 & 16 & 55 \\
\hline lliopsoas & 1 & 1 & 2 & 10 & 7 & 13 & 49 \\
\hline Gluteus medius & - & - & 1 & 9 & 11 & 9 & 40 \\
\hline Sartorius & 4 & 1 & - & 4 & 3 & 3 & 18 \\
\hline Medial collateral ligament & - & 1 & - & 2 & - & 2 & 7 \\
\hline Other & - & - & - & - & $\begin{array}{l}1 \text { Deltoid } \\
1 \text { Quadriceps }\end{array}$ & $\begin{array}{l}1 \text { Fibular } \\
\text { collateral ligament }\end{array}$ & 3 \\
\hline
\end{tabular}
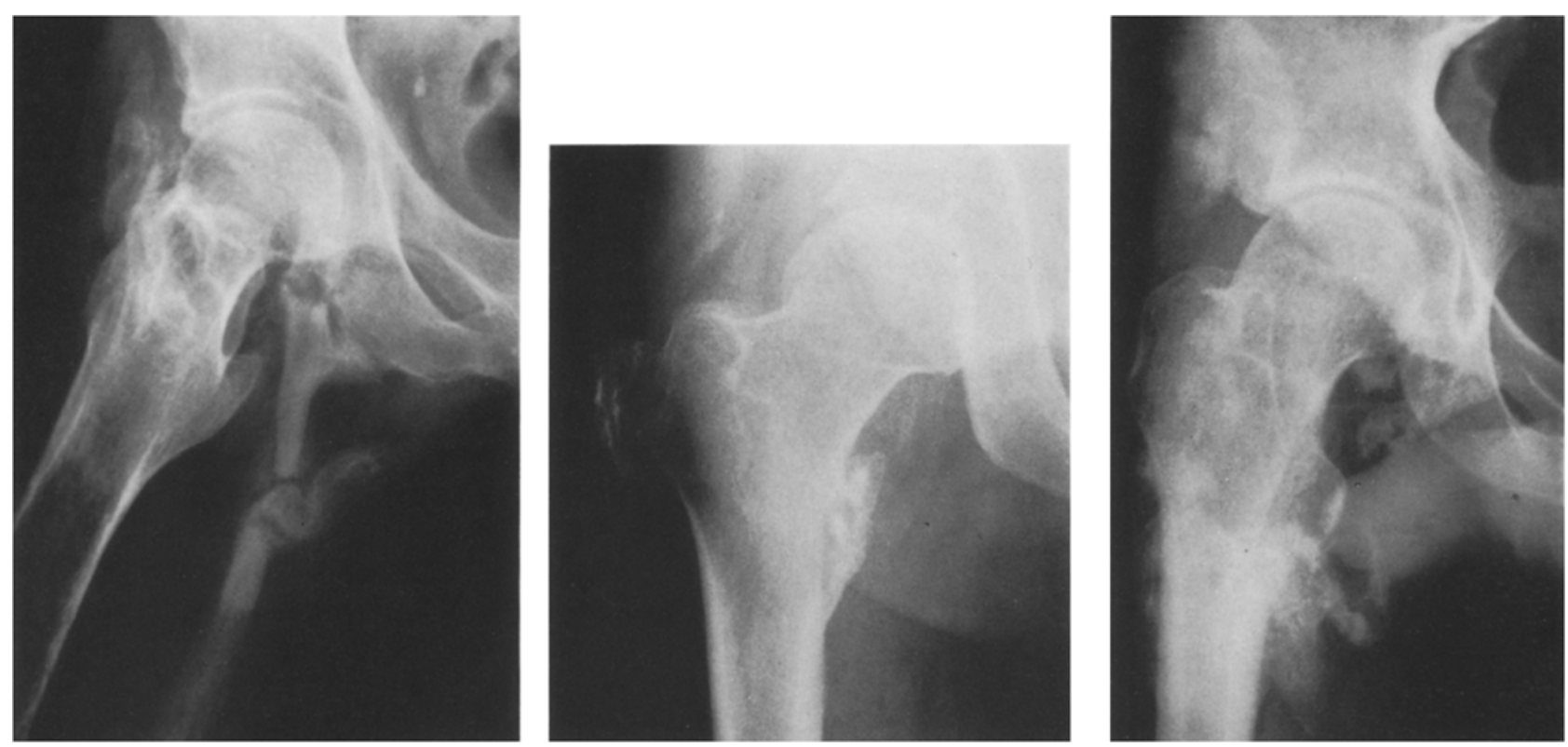

Fig. 6. Heterotopic bone in multiple locations in three different patients

the osseous deposition was found. The majority of the lesions were classified under the following headings: (1) Anterior inferior iliac spine avulsion or rectus femoris injury (Fig. 1). (2) Ischial epiphysiolysis or hamstring or adductor muscle injury (Fig. 2). (3) Avulsion of the lesser trochanter or iliopsoas injury (Fig. 3). (4) Avulsion of the greater trochanter or gluteus medius injury (Fig. 4). (5) Anterior superior iliac spine or sartorius injury (Fig. 5). The heterotopic bone in the 78 patients is classified in this manner in Table 2. Many patients had osseous deposition in several regions (Fig. 6).

The skeleton underlying the heterotopic bone was examined on the roentgenograms. Apart from a variable degree of demineralization in several of the cases, the underlying bone was unremarkable. All true heterotopic bone was found below the level of cord injury. The joint surfaces were preserved.

\section{Discussion}

The diagnosis of true heterotopic bone on clinical examination alone can be difficult. The earliest findings are nonspecific; erythema, edema, and swelling $[11,23]$. The differential diagnosis includes thrombophlebitis, cellulitis, neoplasm, hematoma, periostitis, and osteomyelitis [16, 23, 32]. In order to aid the clinican in this diagnostic problem the radiologist must be able to identify true heterotopic bone associated with spinal cord injuries and separate it from the ectopic bone associated with trauma, osteomyelitis, and neoplasm.

The description by Dejerine and Ceillier [7] in 1918 defined heterotopic bone in the paralyzed patient as bony deposition in the soft tissues. It was found below the level of cord injury, about the joints, but not involving the joint surfaces themselves. The le- 
sions were predominantly at the knee with the pelvis and hip involved to a lesser degree. Urinary tract infection and skin ulcerations were present in the majority of the patients. The authors emphasized the integrity of the underlying skeleton, differentiating this condition from neuropathic joint disease. The etiology was thought to be related to metaplasia of the support tissues secondary to hemorrhage and edema.

Soule in 1945 noted a varying degree of osteoporosis in the skeleton underlying the soft tissue ossifications [29]. Several of his cases of heterotopic bone included fractures with callus formation. All had decubitus ulcers at some time. He proposed trauma from physiotherapy as the cause. Other have supported this view [25].

In 1947 a description appeared in the radiologic literature which emphasized erosive changes in the bones in the vicinity of the osseous deposits [14]. The biopsies of these lesions revealed subacute and chronic infection confirming the suspicion that the authors were describing osteomyelitis. Infection alone [14] or in combination with hypoproteinemia [6] was suggested as the etiology.

In 1963 Hardy and Dickson studied ectopic ossification in paraplegia [13]. They reported soft tissue ossifications in three groups of patients. One group had this finding in association with skin and joint sepsis. A second group had decubitus ulcers. The third group had no known association (though several fractures were included in this group). As they stated, new bone formation constantly occurs in chronic infection so we are not surprised to see it in suppurative arthritis and decubitus ulcers. Silver in 1969 also separated a group of patients with heterotopic bone without evidence of infection or sepsis and called this group true heterotopic ossification [28]. Several authors have noted the major area of involvement at the hip $[6,16,26,31,35]$, unlike Dejerine and Cellier who suggested the knee [7].

Despite the work of Hardy and Dickson, and Silver, most subsequent publications failed to separate true heterotopic bone from ectopic ossification associated with neoplasm, infection, and trauma. No radiographic criteria were established despite the fact that radiographic evidence of soft tissue ossification defined the population studied $[11,15,16,23,31$, 35]. At least four papers describe the soft tissue lesions as calcifications [19, 24, 26, 33], though histopathologically they are true ossifications $[6,8,21]$.

In order to clarify this situation we studied a group of spinal cord injury patients. Seventy-eight out of 376 patients or $20.7 \%$ had true heterotopic bone. No associated infection, neoplasm, or underlying fracture was found in these cases. The usual presenta- tion was at the hip with the knee the second most frequent site of involvement. Although other locations have been reported [35], an unusual location should raise the possibility of a different type of ectopic ossification. In these cases with true heterotopic bone the joint surfaces and underlying skeleton were preserved apart from a variable degree of demineralization.

The etiology of heterotopic bone in the paralyzed patient has long been disputed. Many of the theories suggested by some authors have been refuted by others. A neural factor has been hypothesized many times over the years, but not proved [14, 31]. A recent report trying to group the patients by histocompatibility typing [22], has attempted to relate the osseous deposition to an allergic hypersensitivity response [3]. Major et al. recently suggested an abnormal venous pattern may be present in these patients [20].

Myositis ossificans or fibrositis ossificans circumscripta, is heterotopic bone formation in the supportive tissue of muscle frequently related to direct trauma $[2,3]$. Reports in the literature describe fibrositis ossificans in relation to the ligaments, muscles, or bony attachment. One of the best known examples is ossification of the medial collateral ligament, Pellegrini-Stieda disease $[10,18]$.

The true heterotopic bone in our cases can be related to muscle support systems (Table 2). These areas of involvement have previously been described in association with traumatic fibrositis ossificans [4, $5,9,12,17,27,30,34]$. The underlying mechanism in the paralyzed patient may also be trauma. In these denervated patients, the trauma necessary to produce injury is less obvious than in a neurologically intact patient. The abnormal response of the denervated tissues to trauma, in the production of heterotopic bone, is not understood and may be related to allergic hypersensitivity.

\section{Conclusion}

The similarity of clinical presentation of osteomyelitis, thrombophlebitis, neoplasm, trauma, and true heterotopic bone in the paralyzed patient makes clinical differentiation difficult. The majority of the papers on heterotopic bone in the paralyzed patient fail to separate true heterotopic bone from other ectopic ossification. The usual characteristics of true heterotopic bone are described. The radiologist can suggest the possibility of underlying infection or neoplasm upon recognition of an unusual or atypical presentation of heterotopic bone.

Acknowledgment. The authors wish to thank Dr. John F. Holt for his advice in the preparation of this manuscript. 


\section{References}

1. Abramson AS (1948) Bone disturbances in injuries to the spinal cord and cauda equina (paraplegia). J Bone Joint Surg [Am] $30: 982$

2. Ackerman LV (1958) Extra-osseous localized non-neoplastic bone and cartilage formation (so-called myositis ossificans). J Bone Joint Surg [Am] 40:279

3. Aegeter E, Kirkpatrick JA (1975) Tumors of soft parts. In: Orthopedic diseases physiology pathology radiology. 4th edn. Saunders, Philadelphia

4. Bavendam FA, Nedelman SH (1966) Some considerations in the roentgenology of fractures and dislocations. Semin Roentgenol $1: 407$

5. Bowerman JW (1977) Radiology and injury in sport. 1st edn Appleton-Century-Crofts, New York

6. Damanski M (1961) Heterotopic ossification in paraplegia. J Bone Joint Surg [Br] 43:286

7. Dejerine Mme, Ceillier MA (1918) Para-osteo-arthropathies des paraplegiques par lesion medullaire. Ann Med Interne (Paris) 33:497

8. Dejerine Mme, Ceillier MA, Dejerine Y (1919) Para-osteoarthropathies des paraplegiques par lesion medullaire. Rev Neurol (Paris) 35:399

9. Eastman Kodak Co (1946) Saddle tumors. Med Radiogr Photogr $22: 29$

10. Finder JG (1934) Calcification of the tibial collateral ligament. JAMA 102:1373

11. Furman R, Nicholas JJ, Jivoff L (1970) Elevation of the serum alkaline phosphatase coincident with ectopic-bone formation in paraplegic patients. J Bone Joint Surg [Am] 52:1131

12. Hamsa WR (1957) Epiphyseal injuries about the hip joint. Clin Orthop 10:119

13. Hardy AG, Dickson JW (1963) Pathologic ossification in traumatic paraplegia. J Bone Joint Surg [Br] 45:76

14. Heilbrun N, Kuhn WG (1947) Erosive bone lesions and soft tissue ossifications associated with spinal cord injuries (paraplegia). Radiology 48:579

15. Hsu JD, Sakimura I, Stauffer ES (1975) Heterotopic ossification around the hip joint in spinal cord injured patients. Clin Orthop 112:165

16. Kewlramani LS (1977) Ectopic ossification. Am J Phys Med $56: 99$

17. Kohler A, Zimmer EA (1968) The vertebral column. In: Wilk SP (ed) Borderlands of the normal and early pathologic in skeletal roentgenology. 11th edn. Grune and Stratton, New York

18. Kulowski J (1942) Post-traumatic para-articular ossification of the knee joint (Pellegrini-Stieda's disease). AJR 47:392

19. Liberson $M$ (1953) Soft tissue calcification in cord lesions. JAMA 152:1010

20. Major P, Resnick D, Greenway G (1980) Heterotopic ossification in paraplegia: A possible disturbance of the paravertebral venous plexus. Radiology 136:797

21. Miller LF, O’Neill CJ (1949) Myositis ossificans in paraplegies. J Bone Joint Surg [Am] 31:283

22. Minaire P, Betuel H Philoncher Y (1978) Systeme HLA chez les blesses medullaires atteints de para-osteo-arthropathies neurogenes. Nouv Presse Med 7:3044

23. Nicholas JJ (1973) Ectopic bone formation in patients with spinal cord injury. Arch Phys Med Rehabil 54:354

24. Prakash V, Lin MS, Perkash I (1978) Detection of heterotopic calcification with $99 \mathrm{~m} \mathrm{Tc}$-pyrophosphate in spinal cord injury patients. Clin Nucl Med 3:167

25. Rossier AB, Bussat $P$, Infante F, Zender R, Courvoisier B, Muheim $G$, Donath A, Vasey $H$, Taillard $W$, Lagier $R$, Gabbiani G, Baud CA, Pouezat JA, Very JM, Hachen HJ (1973) Current facts on para-osteo-arthropathy. Paraplegia $11: 36$

26. Rosin AJ (1975) Ectopic calcification around joints of paralysed limbs in hemiplegia, diffuse brain damage and other neurological diseases. Ann Rheum Dis 34:499

27. Schneider R, Kaye JJ, Ghelman B (1976) Adductor avulsive injuries near the symphysis pubis. Radiology 120:567

28. Silver JR (1969) Heterotopic ossification. Paraplegia 7:220

29. Soule AB (1945) Neurogenic ossifying fibromyopathies: A preliminary report. J Neurosurg 2:485

30. Stayton CA (1956) Ischial epiphysiolysis. AJR 76:1161

31. Stover SL, Hathaway CJ, Zeiger HE (1975) Heterotopic ossification in spinal cord-injured patients. Arch Phys Med Rehabil $56: 199$

32. Venier LH, Ditunno JF Jr (1971) Heterotopic ossification in the paraplegic patient. Arch Phys Med Rehabil 52:475

33. Ward WC (1946) Para-articular calcification in the lower extremities of paraplegic patients. AJR 56:712

34. Weitzner I (1935) Fracture of the anterior superior spine of the ilium in one case and anterior inferior in another case. AJR 33:39

35. Wharton GW, Morgan TH (1970) Ankylosis in the paralysed patient. J Bone Joint Surg [Am] 52:105 